\title{
Static load characteristics in the presence of high harmonics
}

\author{
Aleksandr Skamyin ${ }^{1, *}$, and Oleg Vasilkov \\ ${ }^{1}$ Saint-Petersburg Mining University, Electrical Energy and Electromechanics Department, 199106 Saint-Petersburg, 21 line 2, \\ Russia \\ ${ }^{2}$ Saint-Petersburg Mining University, Electrical Engineering Department, 199106 Saint-Petersburg, 21 line 2, Russia
}

\begin{abstract}
The article presents the issues of static load characteristics construction in the presence of high harmonics. Mathematical equations for power calculations in the presence of high harmonics are proposed. Reactive power is calculated at the fundamental frequency based on minimizing the computational error of electronic energy meters and providing minimum costs to ensure maximum degree of reactive power compensation using condenser batteries. The dependences between distortion power and voltage are constructed according to the results of measurements at the laboratory stand. Such dependencies allow us to identify the nature of harmonic distortion, to develop measures for minimizing the distortion power and consumer contribution to the voltage distortion.
\end{abstract}

\section{Introduction}

Currently, many enterprises are experiencing active introduction of electrical equipment, the operation of which results to the high harmonics occurrence in the consumers and energy providers grids [1-7]. Traditionally, calculating the payment for consumed power and electricity is performed in a manner when active and reactive components of power and electricity are accounted for [8]. This is typical for circuits with sinusoidal currents and voltages. What's happening if voltage and current waveforms are other than sinusoidal? Firstly, there are many various scientific theories for calculating and determining power in circuits with nonsinusoidal and unbalanced voltage and current, and the issue on their applicability is still relevant for discussion $[9,10,11]$. Each theory has advantages and disadvantages and is applicable under certain conditions. For example, the pq theory is used in active filters control system for high harmonic compensation and power flows regulation [12]. Secondly, in terms of power metering, electric power meters tested for sinusoidal conditions are currently used under nonsinusoidal conditions. In these conditions power meters can give different readings of active and reactive energy. According to actual standards for active energy meters, there is an accuracy check in the presence of high harmonics. According to standards for reactive energy meters this type of testing is not included.

Power control is a matter of great importance to maintain power quality within the required limits. One way for power consumption control is changing voltage at the consumer's terminals. Static load characteristics can be applied to simulate the possible changing of power system parameters. Static voltage load characteristics are used while calculating steady-state modes and the static stability of power systems. The regulating effect of the load occurs when voltage changes. It resides in changing the consumed active and reactive power [13].

In the presence of high harmonics, it is possible to measure and analyze distortion power flows depending on voltage. In terms of improving the reliability and cost-efficiency of the power system operation, such characteristics are of little interest due to the low content of harmonics in high-voltage grids. However for consumers, such characteristics are important and necessary when selecting means of high harmonics compensation and their impact on electrical equipment.

\section{Methods}

It is important to determine how to conduct calculations of the power in the presence of high harmonics depending on the assigned tasks. These tasks may include determining the rational degree of reactive power compensation, identifying the voltage distortion contribution, reducing the computational error when measuring reactive power, constructing static load characteristics, etc. The construction of static load characteristics is associated with calculating the values of consumed power depending on voltage at the terminals of the electrical equipment. Section 3.1 comprises the most suitable computational equations for the achievement of the assigned task, which were obtained by using simulation modeling via the

\footnotetext{
* Corresponding author: skamin_an@pers.spmi.ru
} 
SimPowerSystems package, as well as on the basis of laboratory studies.

Known are three main methods for determining static voltage load characteristics for consumers: the computational method, the passive experiment method and the active experiment method based on measurements [14]. This paper describes the application of the active experiment method, implemented on a mounted installation in laboratory conditions. The view of the laboratory stand is presented in Figure 1.

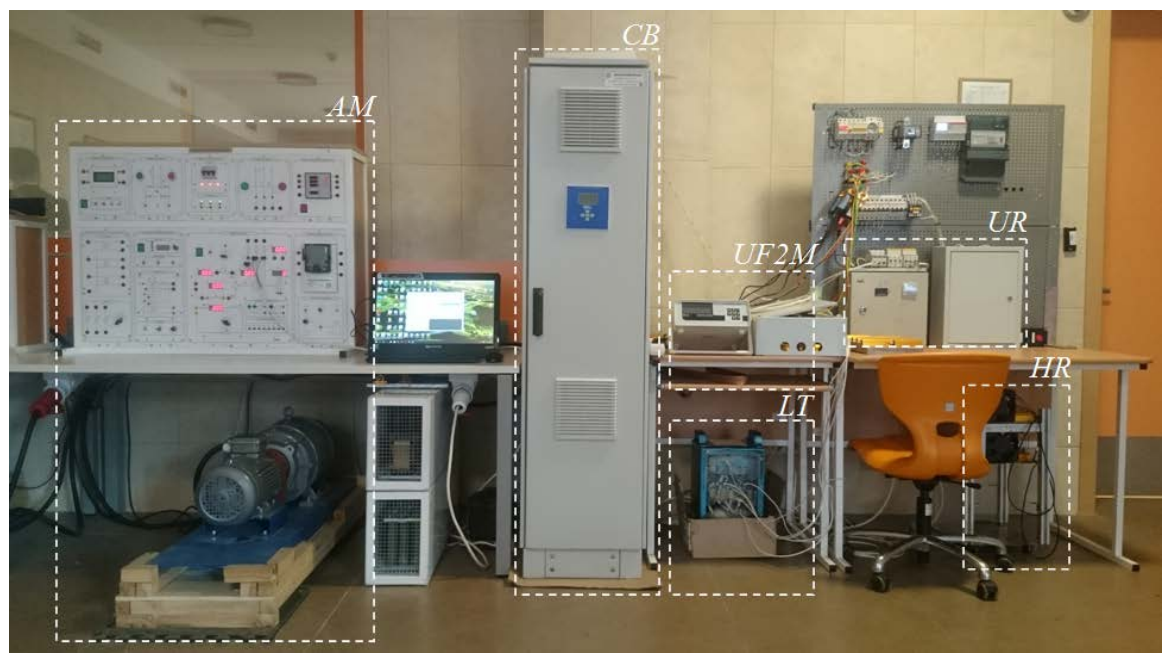

Fig. 1. The view of the laboratory stand.

The laboratory stand includes: three-phase laboratory autotransformer (LT), induction motor with a load in the form of a DC generator (AM), a capacitor battery with an antiharmonic reactor (CB), uncontrolled three-phase rectifier (UR) with a load in the form of active resistance (HR). Measurement of energy consumption parameters was carried out using the power quality analyzer Resurs UF2M.

\section{Results and Discussions}

\subsection{Power components calculation}

In the work [15], various operating modes of electrotechnical complex in the presence of high harmonics were simulated. In this case, reactive power was calculated using the expressions the most widely met in literature sources. The following tasks had to be solved:

1. To determine the computational error in calculating reactive power by different expressions in the presence of high harmonics and compensating devices.

2. To obtain the expression that provides minimum costs to ensure maximum degree of reactive power compensation using condenser batteries in the presence of high harmonics.

As a result of the studies, it was found that determining reactive power according to Kusters \& Moore and IEEE 1459-2010 definitions is the most suitable option in terms of the assigned tasks.

In addition, the work deals with the studies carried out to determine the apparent power component, which characterizes the parameters of the nonlinear electric load. It is shown, that the ratio of the nonlinear loads apparent power of two enterprises, connected to the point of common coupling (PCC), is characterized with a certain error by the ratio of distortion powers at the input connection of these consumers. In this case, the calculation of the distortion power according to IEEE 1459-2010 definition provides the smallest error in estimating the ratio of the nonlinear loads apparent power. This is true only for the same-type rectifiers of enterprises.

It is necessary to consider further whether the ratio of the distortion powers at the input connection of these consumers is an indicator of the voltage distortion contribution in the (PCC).

To this end, in laboratory conditions, the waveforms of the consumed currents were measured at various operating modes of electrical equipment. Two test benches were assembled for the studies with a non-linear electric load in the form of an uncontrolled rectifier with variable parameters of input filters and the DC link, as well as with a non-linear electric load in the form of a frequency-controlled electric motor drive with variable load parameters on the shaft and an input inductance choke. For measurement purposes, the PicoScope 2000 Series oscilloscope with a LTA50-P/SP1 (100mV/1A) transducer that uses the Hall effect to measure direct current and alternating current of complex waveform, was used.

The waveforms of currents and voltages were obtained for six different loads taking into account the phase parameters. Various types of equipment were used as the load, including: uncontrolled rectifier with/without filters and RC load, frequency-controlled drive with different values of mechanical load with/without filter in the form of inductance choke. Mathematical processing of the obtained experimental data was carried out by means of MatLab. The results are presented in the Table 1 , where $\mathrm{n}$ - harmonic number, $\mathrm{I}_{\mathrm{m}}$-amplitude of current, $\psi_{\mathrm{i}}$ - phase of current. 
Table 1. Type of electrical loads and parameters

\begin{tabular}{|c|c|c|c|c|c|c|c|}
\hline Type of load & $\mathbf{n}$ & $\begin{array}{c}\mathbf{I}_{\mathbf{m}}, \\
\%\end{array}$ & $\psi_{\mathrm{i}},{ }^{0}$ & Type of load & $\mathbf{n}$ & $I_{m}, \%$ & $\psi_{\mathrm{i}},{ }^{0}$ \\
\hline \multirow{5}{*}{$\begin{array}{l}\text { Uncontrolled rectifier } \\
\text { with L-filter and RC } \\
\text { load }\end{array}$} & 3 & 38.7 & 72.1 & \multirow{5}{*}{$\begin{array}{l}\text { Frequency-controlled } \\
\text { drive with mechanical } \\
\text { load }(0.5 \mathrm{kVA})\end{array}$} & 3 & 22 & -110 \\
\hline & 5 & 6.6 & 104.7 & & 5 & 33 & 137.5 \\
\hline & 7 & 6.5 & 138.3 & & 7 & 31.9 & -19.6 \\
\hline & 9 & 2.3 & 140.6 & & 9 & 13.4 & -156.6 \\
\hline & 11 & 1.7 & 177.7 & & 11 & 17.1 & 104.9 \\
\hline \multirow{5}{*}{$\begin{array}{l}\text { Uncontrolled rectifier } \\
\text { with RC load }\end{array}$} & 3 & 82.5 & 135.8 & \multirow{5}{*}{$\begin{array}{l}\text { Frequency-controlled } \\
\text { drive with mechanical } \\
\text { load ( } 2 \mathrm{kVA})\end{array}$} & 3 & 3.2 & -89 \\
\hline & 5 & 42 & -73.4 & & 5 & 18.6 & -164.6 \\
\hline & 7 & 6.1 & 89.6 & & 7 & 14 & 26.8 \\
\hline & 9 & 12.9 & 37.9 & & 9 & 1 & -118.1 \\
\hline & 11 & 13.5 & -170.7 & & 11 & 3.6 & -162.8 \\
\hline \multirow{5}{*}{$\begin{array}{c}\text { Uncontrolled rectifier } \\
\text { with LC-filter and RC } \\
\text { load }\end{array}$} & 3 & 55.3 & 66.8 & \multirow{5}{*}{$\begin{array}{c}\text { Frequency-controlled } \\
\text { drive with mechanical } \\
\text { load ( } 0.5 \mathrm{kVA}) \text { and L- } \\
\text { filter }\end{array}$} & 3 & 3.1 & -32.4 \\
\hline & 5 & 18.7 & 36.6 & & 5 & 2.5 & 14.6 \\
\hline & 7 & 5.2 & -3.6 & & 7 & 5.6 & -7.2 \\
\hline & 9 & 1.3 & -62 & & 9 & 0.3 & 18.1 \\
\hline & 11 & 0.5 & 37.4 & & 11 & 1 & -162 \\
\hline
\end{tabular}

For example, the current waveform of frequencycontrolled drive with mechanical load is presented in Figure 2.

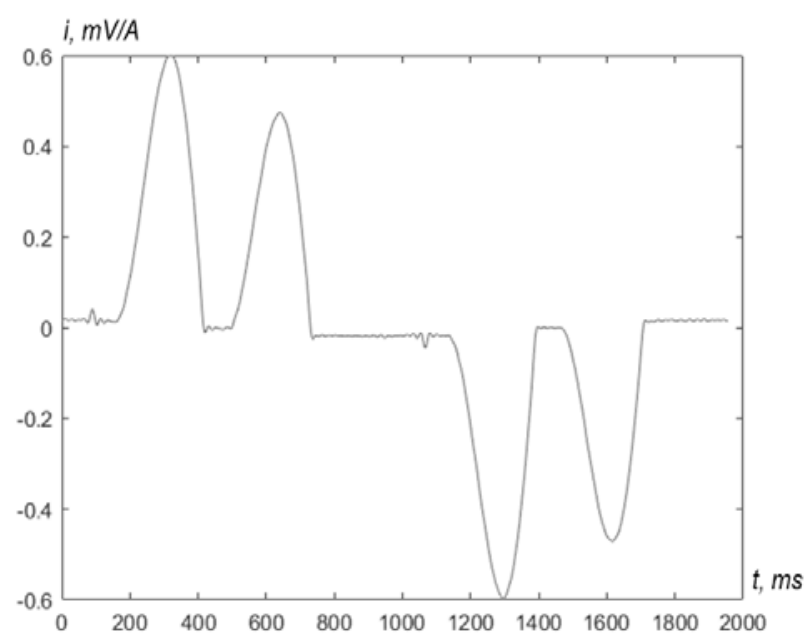

Fig. 2. Current waveform of frequency-controlled drive with mechanical load.

In order to assess the possibility of using current distortion power as an indicator to determine the consumers' contribution to the harmonic voltage component, the grid operating modes with experimentally obtained characteristics of the nonlinear electric load were simulated via the SimPowerSystems software package. Nonlinear electric load is represented by current sources. The electrical grid with two nonlinear electric loads connected to the PCC was considered. Herein, three modes were considered, and in each case the parameters of the nonlinear electric load were set according to the obtained experimental data. For example, in the first mode, nonlinear load parameters were set in the form of an uncontrolled rectifier with an RC load in the DC link with and without an $\mathrm{L}$ filter.

As a result of the simulation, the error in estimating the consumers' contribution to the harmonic voltage components using the current distortion power did not exceed 5\%. It was compared to computation according to the method based on classical Norton scheme for electric circuits.

According to IEEE 1459-2010 nonfundamental apparent power $S_{N}$ can be calculated by equation:

$$
S_{N}=S_{1}\left(T H D_{I}^{2}+T H D_{U}^{2}\right)^{0.5} .
$$

This expression (1) leads to an error of less than $0.15 \%$ for any $T H D_{I}$ under the condition $T H D_{U} \leq 5 \%$. It is also possible to determine $S_{N}$ by the equation:

$$
S_{N}=S_{1} T H D_{I},
$$

This expression (2) leads to an error of less than $1 \%$ under the condition $T H D_{U} \leq 5 \%$ and $T H D_{I}>40 \%$. It follows that under the indicated conditions the distortion power will only slightly differ from the current distortion power.

There are many methods to identify the consumers' contribution to voltage distortion [16-23]. However, the proposed method can be easily implemented in existing power metering systems. So it is possible to perform a preliminary assessment of the consumers' contribution to voltage distortion in the presence of a limited amount of input data.

Let us now consider issues referring to active power. It is known that the active power of high harmonics have a negative value when high harmonics are generated by internal nonlinear electric load, and vice versa, the active power of high harmonics have a positive value when high harmonics are generated by external nonlinear electric load relative to the PCC [18]. In such circumstances, there is unfairness in payments for electricity. A consumer who distorts the supply voltage pays less for active energy. A consumer who does not distort the supply voltage pays more for active energy. However, despite this unfairness, active power should be considered just like that in the case when we determine the distorting consumer by the distortion power. For example, an increase in the power of the internal nonlinear load leads to a decrease in the active power, taking into active power of high harmonics. This leads to 
an increase in distortion power and indicates an increase in the contribution to the voltage distortion.

Thus, it is proposed to construct the static load characteristics in the presence of high harmonics using the active power $P$, taking into account active power of high harmonics $P_{H}$, reactive power at the fundamental frequency $Q_{1}$ and distortion power $D$ :

$$
P=P_{1}+P_{H}, Q=Q_{1}, D=\left(S^{2}-Q_{1}{ }^{2}-P^{2}\right)^{0.5} .
$$

In [24] it was shown that the equation of reactive power balance is correct with sufficient accuracy for practical calculations provided that the $T H D_{U}$ and $T H D_{I}$ values do not exceed 15-20\%. The approach considered in (3) is compliant with the method in [24], taking into account the decomposition of reactive power into the component at the fundamental frequency and the distortion power.

\subsection{Laboratory studies of static load characteristics}

As a result of the studies, the construction of the dependences between consumed power and voltage was carried out using equation (3). The studies were carried out by means of laboratory stand, which is presented in Figure 1.

Three modes of electrical equipment operation were set: electric motor with a rated power of $1.5 \mathrm{~kW}$ at idle and an uncontrolled three-phase rectifier with a load in the form of active resistance with a power consumption of about $1.0 \mathrm{~kW}$ are connected to the grid (mode 1); mode 1 with additionally connected mechanical load to the electric motor (mode 2); mode 2 with additionally connected 1 kvar condenser battery (mode 3).

In all three modes, the voltage ranged from $180 \mathrm{~V}$ to $230 \mathrm{~V}$. As a result, the dependences of the active and reactive power on the voltage were constructed, which are presented in Figure 3.

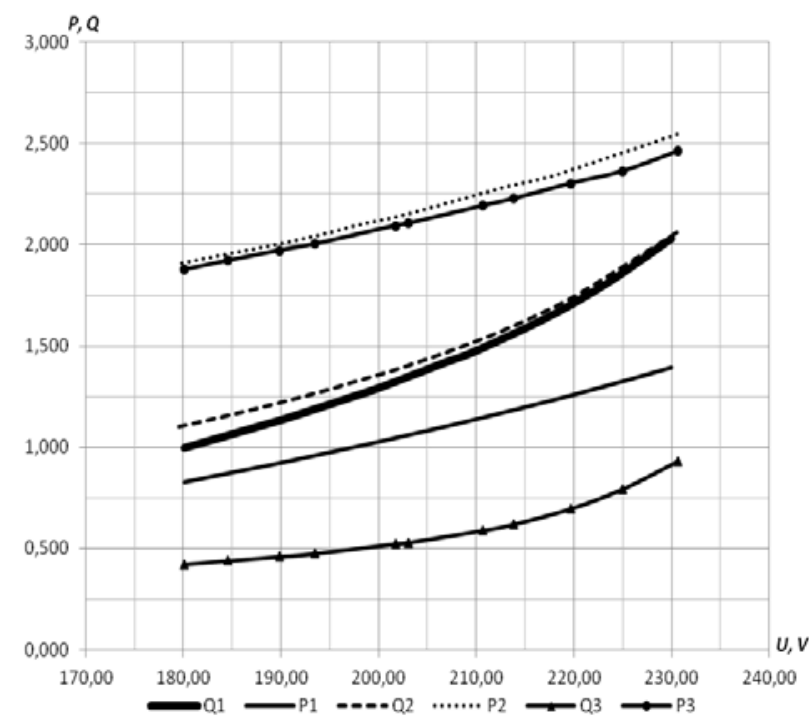

Fig. 3. Static load characteristics $P(U), Q(U)$.

These dependences are not of substantial interest and confirm the patterns of power change from voltage for the adopted load parameters. Distortion power variation depending on the voltage is a more complex process, wherein current and voltage distortions must be accounted for. Figure 4 illustrates the dependences of distortion power, $T H D_{U}$ and $T H D_{I}$ on the voltage.

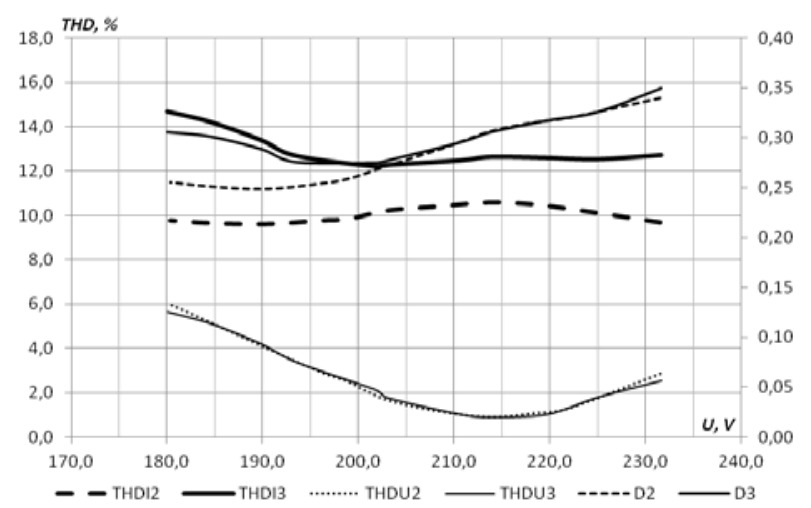

Fig. 4. The dependences between distortion power, $T H D_{U}$, $T H D_{I}$ and voltage.

The diagram shows the dependencies for mode 2 and mode 3. Mode 1 has similar characteristics with mode 2 and it isn `t shown in the diagram. $T H D_{U}$ ranges from 1 to $6 \%, T H D_{I}$ ranges from 9 to $15 \%$ for the conditions under consideration. The distortion power varies from 200 to 350 kvar. A decrease in the voltage leads to an increase in $T H D_{U}$ due to an increase in the system resistance. This is typical for a range of 220 to $180 \mathrm{~V}$. Further increase in voltage results to transformer saturation, which is expressed in an increase in $T H D_{U}$ and a multidirectional change in $T H D_{I}$. The dependence of the distortion power on the voltage repeats the curve of the dependence between $T H D_{I}$ and voltage in the transformer operating range without saturation. This confirms the possibility of calculating the distortion power using $T H D_{I}$ according to equation (2) with some error.

Mode 2 is characterized by a decrease in distortion power and $T H D_{I}$ in the transformer operating range without saturation. Mode 3 in the presence of condenser batteries is characterized by a multidirectional change in distortion power and $T H D_{I}$. Thus, the construction and analysis of dependences between distortion power and voltage allows us to identify the nature of the harmonic occurrence, to develop measures for regulating the distortion power, to minimize the consumers' contribution to the voltage distortion and the influence of high harmonics on electrical equipment operation. However, a pronounced pattern of distortion power variation depending on the voltage is not observed. This confirms the importance of building and analyzing static load characteristics for an individual consumer, as well as conducting additional studies with significant voltage and current distortions.

\section{Conclusions}

1. The most suitable computational equations for static load characteristics construction in the presence of high harmonics were identified. It is proposed to construct the 
static load characteristics using the active power, taking into account active power of high harmonics, reactive power at the fundamental frequency and distortion power.

2. The waveforms of currents and voltages were obtained in laboratory conditions for six different nonlinear loads taking into account the phase parameters. Using the obtained data, a method for identifying a source of high harmonics was revealed based on the calculation of the current distortion power.

3. The static load characteristics in the presence of high harmonics were built with application of the active experiment method, implemented on a mounted installation in laboratory conditions. The construction and analysis of dependences between distortion power and voltage allows us to identify the nature of the harmonic occurrence, to develop measures for regulating the distortion power and to minimize the consumers' contribution to the voltage distortion.

\section{Acknowledgements}

This research has been conducted with financial support from Russian Science Foundation grant (project No. 18-79-00127).

\section{References}

1. B. N. Abramovich and Y. A. Sychev, in Conf. Proc. - 2016 Int. Conf. Actual Probl. Electron Devices Eng. APEDE 2016 (2017)

2. A. A. Belsky and V. S. Dobush, in Proc. 2015 Int. Conf. Mech. Eng. Autom. Control Syst. MEACS 2015 (2016)

3. Y. Zhukovskiy and N. Koteleva, J. Phys. Conf. Ser. 1050, 012106 (2018)

4. V. Y. Koptev, A. V. Kopteva, and D. A. Poddubniy, in 2019 IEEE Conf. Russ. Young Res. Electr. Electron. Eng. (IEEE, 2019), pp. 548-552

5. N. V Obraztsov, V. Y. Frolov, V. E. Popov, D. I. Subbotin, and A. V Surov, J. Phys. Conf. Ser. 1135, 012101 (2018)

6. I. Murashov, V. Frolov, and A. Kadyrov, J. Phys. Conf. Ser. 1058, 012024 (2018)

7. I. V. Murashov, V. Y. Frolov, D. Uhrlandt, S. Gortschakow, D. V. Ivanov, and A. D. Sivaev, Plasma Phys. Technol. J. 4, 124 (2017)

8. S. Pirog, Y. E. Shklyarskiy, and A. N. Skamyin, J. Min. Inst. 237, 317 (2019)

9. P. S. Filipski and P. W. Labaj, IEEE Trans. Power Deliv. 7, 1793 (1992)

10. J. L Willems, in 2010 IEEE Int. Work. Appl. Meas. Power Syst. (IEEE, 2010), pp. 41-46

11. A. Toropchin, V. Frolov, A. V Pipa, R. Kozakov, and D. Uhrlandt, J. Phys. Conf. Ser. 550, 012004 (2014)

12. H. Akagi, E. H. Watanabe, and M. Aredes, Instantaneous Power Theory and Applications to Power Conditioning (John Wiley \& Sons, Inc., Hoboken, NJ, USA, 2007)
13. L. M. Korunovic, J. V. Milanovic, S. Z. Djokic, K. Yamashita, S. M. Villanueva, and S. Sterpu, IEEE Trans. Power Syst. 33, 5923 (2018)

14. S. A. Drimitriev, S. I. Semenenko, and A. A. Suvorov, in 2018 17th Int. Ural Conf. AC Electr. Drives (IEEE, 2018), pp. 1-6

15. A. N. Skamyin and O. S. Vasilkov, in 2019 Electr. Power Qual. Supply Reliab. Conf. 2019 Symp. Electr. Eng. Mechatronics (IEEE, 2019), pp. 1-4

16. P. V. Barbaro, A. Cataliotti, V. Cosentino, and S. Nuccio, IEEE Trans. Power Deliv. 22, 1782 (2007)

17. A. Cataliotti and V. Cosentino, in 2009 IEEE Intrumentation Meas. Technol. Conf. (IEEE, 2009), pp. 426-431

18. L. Kovernikova and R. Shamonov, E3S Web Conf. 25, 04001 (2017)

19. E. D. Kanygina, O. V. Denisova, and I. V. Rastvorova, in 2019 IEEE Conf. Russ. Young Res. Electr. Electron. Eng. (IEEE, 2019), pp. 536-538

20. R. Lin, L. Xu, and X. Zheng, IOP Conf. Ser. Mater. Sci. Eng. 322, 072038 (2018)

21. I. I. Rastvorova, V. A. Krasnorudskii, and I. V. Rastvorova, in 2019 IEEE Conf. Russ. Young Res. Electr. Electron. Eng. (IEEE, 2019), pp. 649-651

22. D. Stevanović and P. Petković, Electr. Eng. 97, 165 (2015)

23. O. S. Vasilkov and V. S. Dobysh, in 2019 IEEE Conf. Russ. Young Res. Electr. Electron. Eng. (IEEE, 2019), pp. 728-730

24. J. Arrillaga, B. C. Smith, N. R. Watson, and A. R. Wood, in Power Syst. Harmon. Anal. (John Wiley \& Sons, Ltd, West Sussex, England, 2013), pp. 33-96 